\title{
Conditions to Prolonged Release of Microencapsulated Carvacrol on Alginate Films as Affected by Emulsifier Type and PH
}

\author{
Silvia Matiacevich, ${ }^{1}$ Natalia Riquelme, ${ }^{1}$ and María Lidia Herrera ${ }^{2}$ \\ ${ }^{1}$ Departamento de Ciencia y Tecnología de los Alimentos, Facultad Tecnológica, Universidad de Santiago de Chile, \\ Obispo Umaña 050, Estación Central, 9170201 Santiago, Chile \\ ${ }^{2}$ Instituto de Tecnología en Polímeros y Nanotecnología ITPN (UBA-CONICET), Facultad de Ingeniería, \\ Universidad de Buenos Aires, Avenida Las Heras 2214, Ciudad Autónoma de Buenos Aires, Argentina
}

Correspondence should be addressed to Silvia Matiacevich; silvia.matiacevich@usach.cl

Received 23 July 2015; Revised 13 October 2015; Accepted 20 October 2015

Academic Editor: Dilip Depan

Copyright ( $(2015$ Silvia Matiacevich et al. This is an open access article distributed under the Creative Commons Attribution License, which permits unrestricted use, distribution, and reproduction in any medium, provided the original work is properly cited.

\begin{abstract}
Alginate from algal biomass is used as edible film and the incorporation of antimicrobial agents improves its performance to increase the shelf-life of fresh foods. However, environmental conditions and intrinsic properties of films influence their release. The aim of this study was to investigate the effect of the concentration and type of encapsulating agent and $\mathrm{pH}$ of emulsions on the physical and antimicrobial properties of alginate-carvacrol films. Films containing alginate, carvacrol as antimicrobial agent, and Tween 20 or trehalose $(0.25$ and $0.75 \% \mathrm{w} / \mathrm{w})$ as encapsulating agents were obtained from suspensions at $\mathrm{pH} 4$ and $\mathrm{pH} 8$. $\mathrm{Physical}$ characterization of emulsions and films and antimicrobial properties (E. coli and B. cinerea) was evaluated. Results showed that droplets size depended on trehalose concentration, but emulsion stability depended on $\mathrm{pH}$ and type of encapsulating agent, being more stable samples with trehalose at $\mathrm{pH}$ 4. Although films with Tween 20 presented the highest opacity, they showed the best antimicrobial properties at initial time; however, during storage time, they lost their activity before samples with trehalose and relative humidity $(\mathrm{RH})$ was the principal factor to influence their release. Therefore, sample formulated with $0.25 \%$ trehalose at $\mathrm{pH}$ 4 and stored at $75 \% \mathrm{RH}$ had the best potential as edible film for fresh fruits.
\end{abstract}

\section{Introduction}

Edible films and coatings can be considered an additional stress factor for preserving food products, assuring its quality as well as an increased shelf-life. The use of edible films is gaining importance in the protection and preservation of fresh food, as they have the ability to contain antimicrobial active ingredients and compounds that can prolong their shelf-life and reduce the risk of pathogen growth on its surface [1-6]. Films and coatings can support antimicrobials agents, but matrix structure stability, concentration of the product on the surface, and gradual release into food are all important characteristics for its functionality; therefore it is important to take into account these characteristics in the use of films or coatings [2].
In development of active edible films and coatings with antimicrobial properties, addition of essential oils (EOs) from herbs and spices has been extensively used as antimicrobial agents. In this sense, Rojas-Graü et al. [7, 8] evaluated the antimicrobial activities against E. coli O157:H7 of several EOs (oregano, cinnamon, and lemongrass) and active oil compounds (OCs), such as carvacrol, cinnamaldehyde, and citral, incorporated on alginate-apple puree edible film in concentrations lower than $0.5 \% \mathrm{w} / \mathrm{w}$. In those systems, carvacrol exhibited the strongest antimicrobial activity as measured by the film disk agar diffusion assay as a qualitative test for antimicrobial activity of the films. Besides, optimal antimicrobial effects were observed using carvacrol concentration of $1.0 \% \mathrm{w} / \mathrm{w}$ added to the initial apple [9] and tomato [10] films preparation against E. coli O157:H7. 
Hernández-Ochoa et al. [11] studied cumin, clove, and elecampane essential oils added to chitosan films, reporting that clove EO $(2 \% \mathrm{w} / \mathrm{w})$ can be considered for the preparation of active packing material. In addition, antioxidant properties from EOs are reported in gelatin based edible films [12]. Many studies are conducted in order to improve shelf-life of many fresh foods using EOs and OCs added to edible films or coatings. For example, for refrigerated chicken meat, rosemary oil incorporated into cellulose acetate based film was successfully used [13]. Oregano and clove oil added into whey protein isolate coating [14] and thyme oil in alginate coating were also investigated [15]. It was reported that films and coatings based on alginate containing cinnamon, palmarosa, and lemongrass and their main OCs improved the shelf-life and safety of fresh-cut "Piel de Sapo" melon [16] and that films containing eugenol and citral as OCs reduced microbial spoilage and preserved sensory properties of Arbutus unedo L. berries fruit [17]. Besides, lemongrass, oregano, and vanillin oil incorporated into an apple pureealginate edible coatings were used for extending shelf-life of fresh-cut "Fuji" apples [18]. However, despite the lipophilic and volatile nature of the above mentioned compounds (EOs and OCs), authors did not use any type of emulsifier or encapsulating agent. It is important to remark that they can evaporate easily and decompose during preparation of these films and coatings, due to direct exposure to heat, pressure, light, or oxygen [19]. Carvacrol, the major component (50$86 \%$ ) of oregano essential oil (Origanum sp.) [20, 21], is a phenolic compound. Its antimicrobial properties have been demonstrated in numerous studies also against bacteria [7$10,22-25]$, mold $[25,26]$, and yeast $[25,27]$.

Edible films and coatings are based on proteins, polysaccharides, and lipids [28]. Among widely used polysaccharides, alginates are natural polysaccharides extracted from brown algal biomass (Phaeophyceae), and it is a salt of alginic acid composed of two uronic acids: $\beta$-D-mannuronic acid (M) and $\alpha$-L-guluronic acid (G). Principal applications are based on its gel-forming ability through calcium interactions, as food additives (E400 $\cdots$ E405 in Europe) and in the last years as principal matrix of edible films and coatings [5, $7,8,15-18,22,29-32]$. Taking into account that alginate films are hydrophilic matrices, the crosslinking process with polyvalent cations as calcium has been used to improve their water barrier properties, mechanical resistance, cohesiveness, and rigidity [31, 32]. Benavides et al. [22] suggested that physical, mechanical, and antibacterial properties of alginate films can be modified by controlling the level of internal crosslinking produced by the addition of $\mathrm{CaCO}_{3}$. Therefore, the addition of $\mathrm{CaCO}_{3}$ as crosslinker matrix in this study instead of $\mathrm{CaCl}_{2}$ could permit a slower rate of diffusion of carvacrol into the agar as a result of the higher level of internal crosslinking achieved by the alginate matrix [22].

In order to maintain the antimicrobial properties in the film during prolonged time, encapsulation of lipid compounds (OCs) could be used, which improves the stability of the lipid, since it is a medium that provides physical protection against oxidation without antioxidants; therefore, the choice of encapsulating agent and/or emulsifier is critical, which influences the stability of the emulsion [33]. Tween 20 has been reported to be the most widely used emulsifier in the formation of emulsions and nanoemulsions [15], while the physicochemical properties of trehalose have been reported to be very promising concerning its use for microencapsulation [33]. In the other way, the storage conditions could also affect both physical and antimicrobial properties of the film $[34,35]$.

It is important to remark that the processing conditions of film forming suspensions, film composition, and the possible interactions between the film forming biopolymer and the other food components present in the matrix could affect additive migration and, as a consequence, its effectiveness as antimicrobial. For some applications, a quick release of the antimicrobial is required to control microbial growth in food. On the contrary, in other applications, a slow release is required so as to assure a certain level of the preservative at the surface to control the external contamination. The determination of the rate of release together with the evaluation of antimicrobial activity through the time might help to optimize the development of films and coatings as a potential active packaging material. One of the experimental design techniques to achieve this aim is the central composite rotatable design (CCRD) of response surface methodology (RSM), an effective and versatile methodological tool for the determination of optimum levels of the processing variables for the parameters studied.

Therefore, the aim of this study was to evaluate the effect of the type of emulsifier on physical, optical, and morphological properties together with antimicrobial (antibacterial and antifungal) gradual activity of alginate based films containing carvacrol during different storage conditions, in order to obtain a prolonged release of the antimicrobial agent as potential applications on coating active material. The central composite rotatable design (CCRD) of RSM was used as a statistical method to optimize the storage conditions of edible films, maximizing inhibition of bacterial growth and minimizing variation of optical properties.

\section{Materials and Methods}

2.1. Materials. The materials used for film formation included food-grade sodium alginate purchased from Sigma-Aldrich Chemical Co. (St. Louis, MO, USA); sorbitol (used as a plasticizing agent) obtained from Blumos (Santiago, Chile); calcium carbonate used in the crosslinking process and purchased from Winkler Ltda. (Santiago, Chile). The antimicrobial agent used in the present work was carvacrol (282197, Aldrich Company, Inc., USA) with a purity of $\geq 99.5 \%$. Two different encapsulating agents were used: a synthetic one, Tween 20 (used as a surfactant) from Merck Co. (Darmstadt, Germany), and a natural one, trehalose (Blumos, Santiago, Chile). Sodium hydroxide (Aldrich Company, Inc., USA) was used to adjust $\mathrm{pH}$ of film forming emulsions. All reagents were analytical grade.

2.2. Microorganisms and Media. Antimicrobial characteristics of different films were measured following growth of E. coli (ATCC 25922), obtained from the Institute of Public Health (ISP, Santiago, Chile). 
Antifungal activity of edible films was evaluated against Botrytis cinerea, which causes the grey mould disease and is one of the most serious diseases of a wide range of crops of worldwide importance. Postharvest losses are important due to development of this fungus during the storage and distribution of harvesting fruits [36]. B. cinerea were isolated from spoiled blueberries var. Brigitta, bought in local market (Santiago, Chile), and were inoculated on PDA medium (Potato Dextrose Agar, Biokar Diagnostics, France) and incubated at $25^{\circ} \mathrm{C}$ for 7 days until obtaining a pure culture (2 inoculations). Amongst the isolated strains, Botrytis cinerea were identified at the laboratory according to macroscopic criteria [36], and fresh cultures of 5 days were used for antifungal measurements.

2.3. Film Forming Emulsions (FFE) and Film Casting. Film forming emulsions using distilled water as solvent were prepared based on the following: $1 \% \mathrm{w} / \mathrm{w}$ sodium alginate, $1 \% \mathrm{w} / \mathrm{w}$ sorbitol (as plasticizer), and the antimicrobial agent carvacrol $0.5 \% \mathrm{w} / \mathrm{w}$ (concentration obtained previously through minima inhibition concentration (MIC), taking into account the presence of $1 \% \mathrm{w} / \mathrm{w}$ sodium alginate). Encapsulating agents were incorporated into FFE as the following concentrations: 0.25 and $0.75 \% \mathrm{w} / \mathrm{w}$ of trehalose and $1 \% \mathrm{w} / \mathrm{w}$ of Tween 20. Lower concentrations of encapsulating agents did not allow droplets formation, while higher concentrations of them modified opacity or visual appearance of films, which could affect organoleptic characteristics of the products coated with these FFE. These FFE were homogenized at room temperature for $1 \mathrm{~min}$ at $10.000 \mathrm{rpm}$ using homogenizer (Ultraturrax Thristor Regler TR50, Germany). Then, calcium carbonate $0.02 \% \mathrm{w} / \mathrm{w}$ (as alginate crosslinker agent) was added using magnetic stirrer and the $\mathrm{pH}$ was adjusted at 4 and 8 . The selected $\mathrm{pH}$ is the endpoints of the interval growth of both microorganisms. Vacuum was then applied in suspensions to remove bubbles. Films were obtained by warm casting; briefly $40 \mathrm{~mL}$ of FFE was put on Petri plates $9 \mathrm{~cm}$ in diameter and dried in an oven at $40^{\circ} \mathrm{C}$ for $20 \mathrm{~h}$. Dried films were peeled from the casting surface. The thickness of each film was measured with a micrometer (Mitutoyo, Japan). Measurements were taken at five different places on the film and an average value of $0.12 \pm 0.02 \mathrm{~mm}$, showing uniform films.

These samples were used for determinations of physicochemical and antimicrobial properties of the films during storage time.

\subsection{Characterization of FFE}

2.4.1. Diameter Size of Droplets. One of the most important properties to characterize the FFE is the interfacial area of the droplets or average diameter of them, which is represented by Sauter diameter $\left(D_{32}\right)$ [37]. It was estimated using (1) [38]. The average droplet diameter of the different FFS was calculated from images in an optical microscope with a calibrated scale at 40x (Carl Zeiss, Germany) using Motic Images Plus (v.2.0, Digital Microscopy Software, Motic China Group Co., Ltd.). At least 100 droplets were measured by quintuplicate of each
FFE and the mean of data with their corresponding standard deviation is reported:

$$
D_{32}=\frac{\sum_{i=0}^{n} n_{i} d_{i}^{3}}{\sum_{i=0}^{0} n_{i} d_{i}^{2}},
$$

where $D_{32}$ is average droplet diameter Sauter, $n_{i}$ is number of drops, and $d_{i}$ is internal diameter $(\mu \mathrm{m})$.

2.4.2. Stability of Emulsion. The stability of FFE was analyzed using a vertical scan analyzer Turbiscan MA 2000 (Formulaction, France) at different times during storage at $40^{\circ} \mathrm{C}$. The samples were put in a cylindrical glass measurement cell and the backscattering (BS) profiles as a function of the sample height (total height $=70 \mathrm{~mm}$ ), acquiring data every $40 \mu \mathrm{m}$, were studied in quiescent conditions at $23 \pm 2^{\circ} \mathrm{C}$. In this way, physical evolution of this process is followed without disturbing the original system and with good accuracy and reproducibility. Measurements were performed immediately after preparation of the emulsions by triplicate. Global stability was followed by measuring the BS mean values as a function of storage time in the middle zone of the tube [39]. The optimum zone was the one where no significant transmitted light was detected, that is, $20-60 \mathrm{~mm}$ for all samples.

\subsection{Characterization of Films}

2.5.1. Moisture Content. Moisture content of films was determined by gravimetric methodology, using an analytical balance (Mettler Toledo, Switzerland) and an oven (Wiseven Daihan Scientific WOF-105, Korea) at $105^{\circ} \mathrm{C}$ for $24 \mathrm{~h}$ until reaching constant weight (differences less than $0.5 \%$ ). The analysis was performed by quadruplicate and the moisture content was expressed in \% wet basis ( $\mathrm{g}$ water/100 g wet sample) as the main value with their corresponding standard deviation.

2.5.2. Color and Opacity. The visual properties of the films can affect appearance of the products and determine acceptability for consumers. Digital images from each film (white and black background) were captured through a computer vision system (CV) setup, which consisted of a black box with four natural daylight (D65) tubes of $18 \mathrm{~W}$ (Philips) and a camera (Canon 14 MP PowerShot G3) placed in vertical position at $22.5 \mathrm{~cm}$ from samples. The camera lens angle and light were $45^{\circ}$, according to Pedreschi et al. [40] and Matiacevich et al. [41]. All images were acquired at the same conditions; the camera was remotely controlled by ZoomBrowser software (v6.0 Canon). Camera was calibrated using 30 color charts with a Minolta colorimeter [41]. Color data were obtained in the RGB (red-green-blue) space using Adobe Photoshop v7.0 program and convert into $\mathrm{CIEL}^{*} a^{*} b^{*}$ space standard. Therefore, values of color parameters, lightness $\left(L^{*}\right)$, and chromaticity parameters $a^{*}$ (red-green) and $b^{*}$ (yellowblue), of each film obtained from image analysis, were equal as those values from the colorimeter. Variation of colors between each films and control film (without carvacrol) was calculated using CIEDE2000 equation [42, 43]. 
Film opacity is a critical property of the film if the film or coating is to be used over the surface of food. The opacity is indicative of the amount of light that can pass through the material and was determined by the Hunter lab method, using the values of lightness $\left(L^{*}\right)$ obtained from the films using white ( $L^{*}$ white) and black $\left(L^{*}\right.$ black) background:

$$
\text { Opacity }=\frac{L^{*} \text { black }}{L^{*} \text { white }} \text {. }
$$

Data reported were the average of five films of each sample with their corresponding standard deviation.

2.5.3. Percentage of Carvacrol Release by DSC. The percentage of release $(\% R)$ of pure carvacrol from films was determined as the ratio of the fusion enthalpy of films containing carvacrol at time zero, already formed (corrected according to the water content of the samples), and the fusion enthalpy of the pure compound, as indicated in (3) [44]. The fusion enthalpy was determined by differential scanning calorimeter (DSC Diamond, Perkin Elmer, USA). The range of working temperatures was $-50^{\circ} \mathrm{C}$ to $80^{\circ} \mathrm{C}$ with a heating rate of $10^{\circ} \mathrm{C} / \mathrm{min}$ and cooling rate of $40^{\circ} \mathrm{C} / \mathrm{min}$. Samples films ( $\sim 10 \mathrm{mg})$ were placed in hermetically sealed capsules:

$$
\% R=\frac{\Delta H_{S}}{\Delta H_{0}},
$$

where $\Delta H_{S}$ is heat of melting of carvacrol in the film and $\Delta H_{0}$ is heat of melting of pure carvacrol.

The calculated confidence interval for a $95 \%$ certainty was between $5 \%$ and $7 \%$ of the absolute values.

2.5.4. Molecular Mobility. Transversal or spin-spin relaxation times $\left(T_{2}\right)$ were used to determine water and solids mobility and were measured by time resolved ${ }^{1} \mathrm{H}-\mathrm{NMR}$ in a Bruker Minispec mq20 (Bruker Biospin Gmbh, Rheinstetten, Germany) with a $0.47 \mathrm{~T}$ magnetic field operating at a resonance frequency of $20 \mathrm{MHz}$ and at $30^{\circ} \mathrm{C}$. Proton populations of different mobility were measured using the free induction decay (FID) for protons from solid matrix or from water strongly interacting with the solid matrix [45], under the following conditions: pulse sequence employing a $2.74 \mu \mathrm{s}, 90^{\circ}$ pulse length and a $5.06 \mu \mathrm{s} 180^{\circ}, 4$ scans, and relaxation delay of $2 \mathrm{~s}$.

Films were placed in $10 \mathrm{~mm}$ diameter glass tubes (to $5 \mathrm{~cm}$ height) and were previously equilibrated at $30.00 \pm$ $0.01^{\circ} \mathrm{C}$ in a thermal bath (Haake, model Phoenix II C35P, Thermo Electron Corp., Germany). The FID test itself is very fast, taking $10 \mathrm{~s}$, and samples could be measured without appreciable temperature modification. The decay envelopes were fitted to monoexponential behavior.

2.5.5. Microstructural Characteristics of Surface (SEM). Scanning electron microscopy (SEM, Supra 40, Carl Zeiss NTS) is used to evaluate microstructural characteristics of the surface and cross sections of all films such as film homogeneity and surface smoothness. Dried samples $(5 \times 3 \mathrm{~mm})$ were mounted on specimen stubs. Samples were freeze-dried, platinum coated, and observed using an accelerating voltage of $15 \mathrm{kV}$. For cross section observation, the samples were previously fractured using liquid nitrogen.

2.5.6. Surface Hydrophobicity. The surface hydrophobicity of the films was determined by the drop method, based on optical contact angle method. Contact angle measurements were carried out with an optic system, which comprised zoom video lens (Edmund Optics, NJ, USA) connected to a CCD camera (Pulnix, Inc., San Jose, CA, USA), controlled via software. Drops $(5 \mu \mathrm{L})$ of ethyleneglycol (Aldrich Co.) were manually deposited on the film surface. An image analyzer (software ImageJ with the plugin Drop Shape Analysis) was used to measure the angle formed between the surface of the film in contact with the droplet and the tangent to the droplet at the point of contact with the film surface. The measurements (in both sides of the droplet) were performed within the first $15 \mathrm{~s}$ after dropping ethyleneglycol onto film surfaces, to avoid variations due to solvent penetration onto the specimens. Seven measurements were performed for each film at room temperature.

\subsection{Antimicrobial Properties of the Films}

2.6.1. Escherichia coli. Escherichia coli (ATCC 25922) was stored at $-20^{\circ} \mathrm{C}$ in Mueller Hinton broth with $20 \%$ w/w skim milk until use. Bacteria culture was obtained by an inoculum in Mueller Hinton broth (DIFCO, France) at $37^{\circ} \mathrm{C}$ overnight. This culture served as the inoculums for the microbiological studies. The colony-forming units (CFU) counts were accurately and reproducibly obtained by absorbance value measured by optical density at $625 \mathrm{~nm}$ on a spectrophotometer (Shimadzu UVmini-1240, Japan), which corresponded to a $0.5 \mathrm{McF}$ arland turbidity standard solution (approximately $10^{8} \mathrm{CFU} / \mathrm{mL}$ ) [46], and diluted with a final concentration of $10^{3} \mathrm{CFU} / \mathrm{mL}$.

The antibacterial activity of the films with carvacrol was determined using the agar diffusion method, according to Benavides et al. [22]. Briefly, the edible films were aseptically cut into $2 \mathrm{~mm}$ squares and placed on Muller Hinton agar plates, which had been previously spread with $1 \mathrm{~mL}$ of inoculum, each containing $10^{3} \mathrm{CFU} / \mathrm{mL}$ of bacterial culture. The plates were incubated at $37 \pm 1^{\circ} \mathrm{C}$ for $24 \mathrm{~h}$. The diameter of the growth inhibition zones (inhibition halo) around the films was measured using a digital caliper (VWR, USA). The growth under the film discs (area of contact with the agar surface) was visually examined. The measurements were made in quadruplicate for each film.

2.6.2. Botrytis cinerea by Vapour Contact Assay. Considering the volatile characteristic of essential oils and their components, antifungal properties were observed using vapour contact [47-50]. The effect of volatile oil fraction from films was studied with invert Petri dishes method. PDA medium was poured into $90 \mathrm{~mm}$ of Petri dish and spot inoculated to Botrytis cinerea. A film slice $(1 \mathrm{~cm}$ size) was placed into the cover of each Petri dish, so that it does not directly touch the surface of agar medium. The space inside of the 
TABLE 1: Coded and actual values for independent factors $\left(X_{1}\right.$, $X_{2}, X_{3}$ ) with 5 levels used in the experimental (central composite rotatable (CCRD)) design.

\begin{tabular}{|c|c|c|c|c|c|}
\hline & \multicolumn{5}{|c|}{ Coded value } \\
\hline & $-\alpha(-1.68)$ & -1 & 0 & +1 & $+\alpha(+1.68)$ \\
\hline & \multicolumn{5}{|c|}{ Actual values } \\
\hline \multicolumn{6}{|l|}{ Factors } \\
\hline $\mathrm{pH}, X_{1}$ & 4.8 & 4 & 6 & 7.2 & 8 \\
\hline Temperature $\left({ }^{\circ} \mathrm{C}\right), X_{2}$ & 4 & 10 & 20 & 25 & 30 \\
\hline Relative humidity (\%), $X_{3}$ & 75 & 85 & 87 & 94 & 100 \\
\hline
\end{tabular}

sealed Petri dish was calculated to be $70 \mathrm{~mm}^{3}$ of air. A positive control of fungal growth was included containing inoculated PDA medium. Inhibition percentage of growth was calculated comparing fungal growth of each sample with positive control.

\subsection{Data Analysis and Modeling}

2.7.1. Experimental Design and Storage Conditions. The storage conditions of films were optimized using the 3-factor-5level central composite rotatable design (CCRD), of response surface methodology (RSM) software (Statgraphics Centurion XVII). The design required 17 runs derived from 8 combinations of the independent variables performed in random order, including 3 replicates at the central point and two axial points (one variable axis at a distance of 1.68 from the center). The 3 replicates at the central point were used to determine the experimental error and the variance and check the fit. The three depended responses $(\mathrm{pH}$ of FFE, relative humidity, and temperature), levels, and experimental design in terms of studied values can be observed in Table 1. The experimental points were calculated as functions of the range of interest of each factor: temperature in the range of $4-30^{\circ} \mathrm{C}$ in order to evaluate the possible temperatures of commercial storage, $\mathrm{pH}$ between 4 and 8 , and relative humidity $(\mathrm{RH})$ from 75 to $100 \%$ and also $\mathrm{RH}$ of commercial storage, using the corresponding saturated salts [51]. Optima conditions were obtained using the optimization module of RSM software for each factor and for multiple responses taking into account the minima variation of color and opacity of films and the maxima inhibition of bacteria growth. All experiments were performed in randomized order to minimize bias effect. The experimental and predicted values were compared in order to determine the validity of the developed model. The verification of model was performed similar to the method applied by previous study.

2.7.2. Statistical Analysis. ANOVA was performed to determine the differences between the encapsulating types in terms of the parameters studied using GraphPad Prism version 5.03 (GraphPad Prism Inc.). Significant differences between the emulsifier types were further analyzed using Tukey's Multiple Test (GraphPad Prism v5.03). The significance of the difference was determined at a $95 \%$ confidence level $(P<0.05)$.

\section{Results}

The characterization of film forming emulsions and films was evaluated in order to compare different concentrations and types of encapsulating agents $(0.25$ and $0.75 \%$ trehalose and $1 \%$ Tween 20) at different $\mathrm{pH}$ (4 and 8). Then, films were stored for 14 days in order to obtain the best conditions for prolonged release of the microencapsulated carvacrol from the films.

3.1. Characterization of Film Forming Emulsions. The droplet size of each emulsion containing thyme oil and alginate using different encapsulating agents was measured since they might have a relevant impact on features such as color and mechanical properties of edible films [29]. The mean value obtained at initial time from droplet sizes $\left(D_{32}\right)$ was $0.6 \pm$ $0.2 \mu \mathrm{m}$ for samples containing $0.25 \%$ of trehalose or $1 \%$ of Tween 20 and $0.3 \pm 0.2 \mu \mathrm{m}$ for samples with $0.75 \%$ of trehalose, independently of $\mathrm{pH}$ of emulsions. Though the high polydispersity of droplet diameters, statistical analysis shows significant differences at $95 \%$ of confidence in the diameter of droplets between both concentrations of trehalose. The high polydispersity is related to oil polarity, different interactions between components, viscosity, and solubilization rate which can influence the resulting droplet size $[29,52,53]$.

The stability of the film forming emulsions (FFE) is an important factor regarding edible coatings, especially in relation to commercialization and their application by spraying process on fresh foods. The stability of emulsions was measured at $40^{\circ} \mathrm{C}$ because it is the temperature of casting methodology. The instability of a colloidal dispersion increases at elevated temperatures, which is attributed to accelerated Ostwald ripening and/or coalescence processes by changes in nonionic surfactant properties [53]. Therefore, $40^{\circ} \mathrm{C}$ was also selected in order to accelerate the instability process. The results of analysis of emulsions stability at different $\mathrm{pH}$ of final FFE and different type and concentrations of encapsulating agents are shown in Figure 1. In the first place, the principal instability process observed for Tween 20 emulsions, as diminution of backscattering, was coalescence/flocculation and/or Ostwald ripening at both $\mathrm{pH}$, being significantly lower at $\mathrm{pH} 4(0.5-5 \%)$ comparing to $\mathrm{pH} 8$ (5-12\%). Regarding type of encapsulating agents, Tween 20 is the highest instable FFE, showing, besides, sedimentation at both $\mathrm{pH}$. Comparing emulsions with different concentrations of trehalose at $\mathrm{pH}$ 4 it may be noticed that the destabilization mechanism was creaming for $0.25 \%$ trehalose and coalescence for $0.75 \%$ trehalose, while for $\mathrm{pH} 8$ the behavior was the opposite: $0.25 \%$ trehalose destabilized by coalescence and $0.75 \%$ trehalose by creaming. These results showed the relevance of $\mathrm{pH}$ in emulsions components interactions.

3.2. Characterization of Films at Initial Time. Moisture content of films after casting was in the range of 12 to $18 \%$ (dry basis). No significant differences $(P>0.05)$ were found for the type of encapsulating agent, concentration, or $\mathrm{pH}$ of the samples.

In order to obtain the variation of color of films (CIEDE2000), color parameters $\left(L^{*}, a^{*}, b^{*}\right.$, Hue, and Croma) 

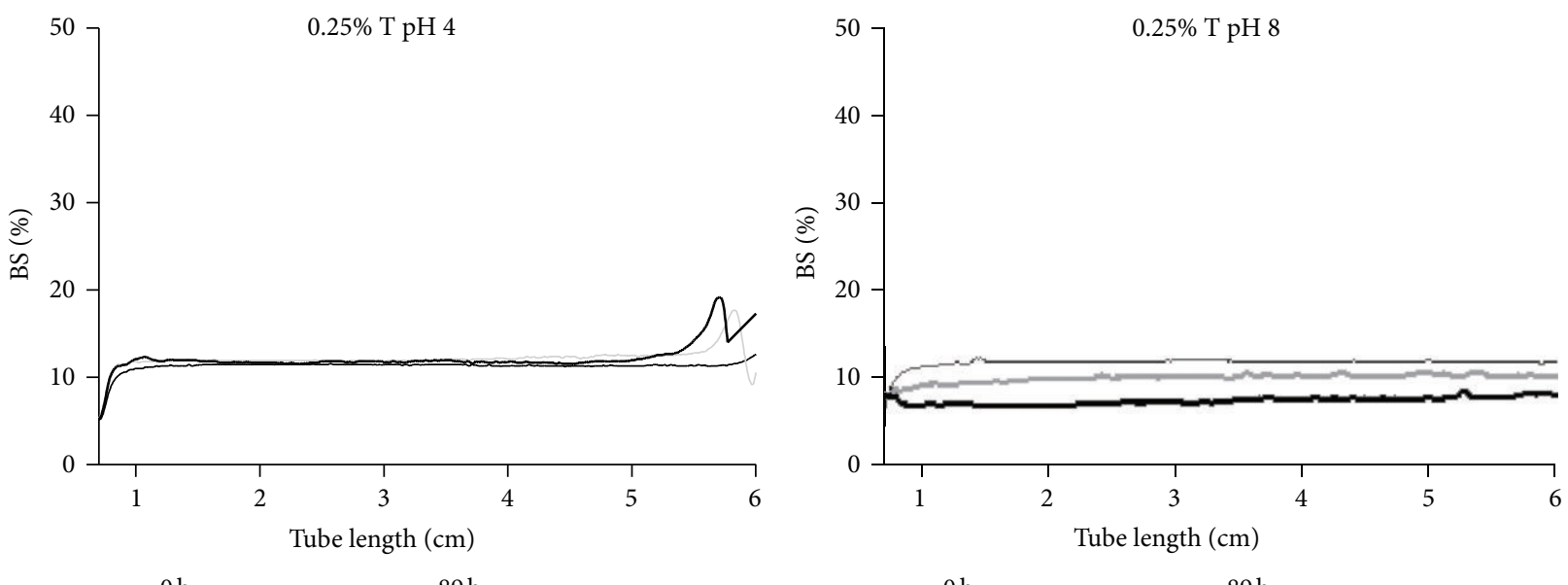

$-0 \mathrm{~h}$

$-89 \mathrm{~h}$

- $0 \mathrm{~h}$

$26 \mathrm{~h}$

(a)

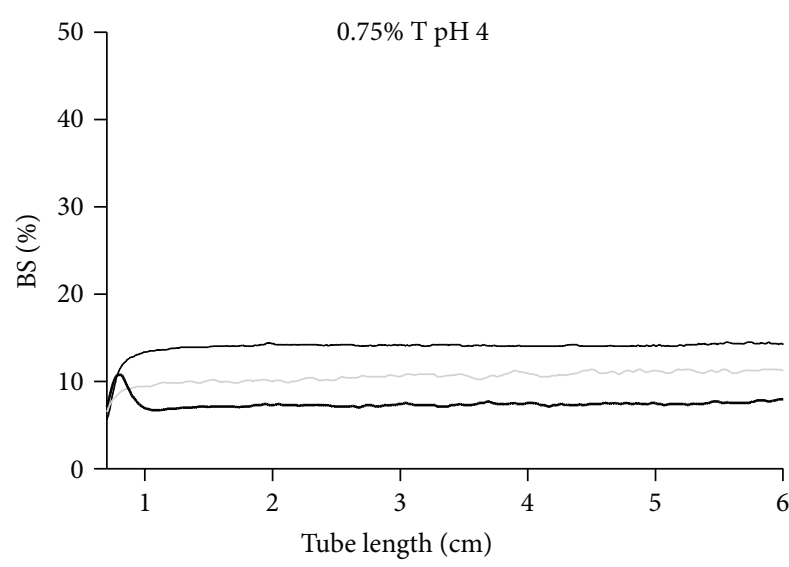

$-0 \mathrm{~h}$

$-26 \mathrm{~h}$

(c)

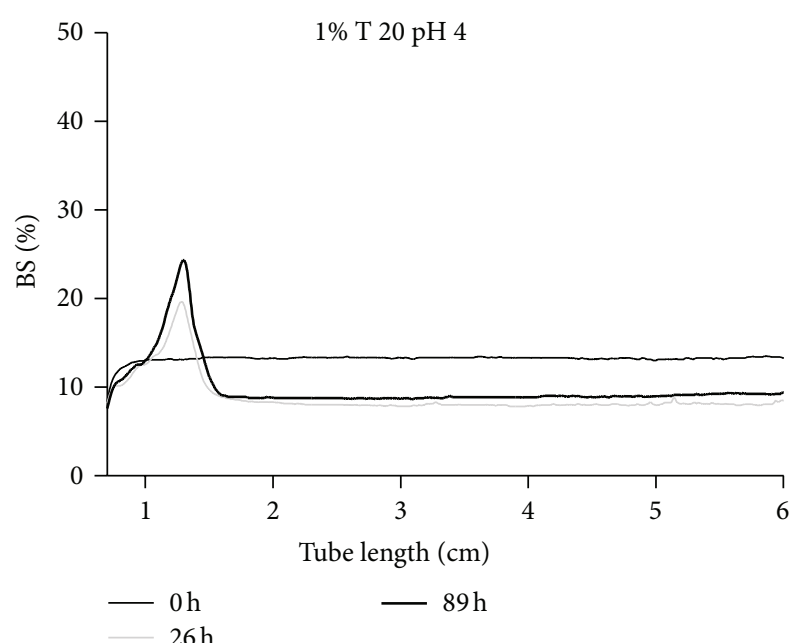

(e)

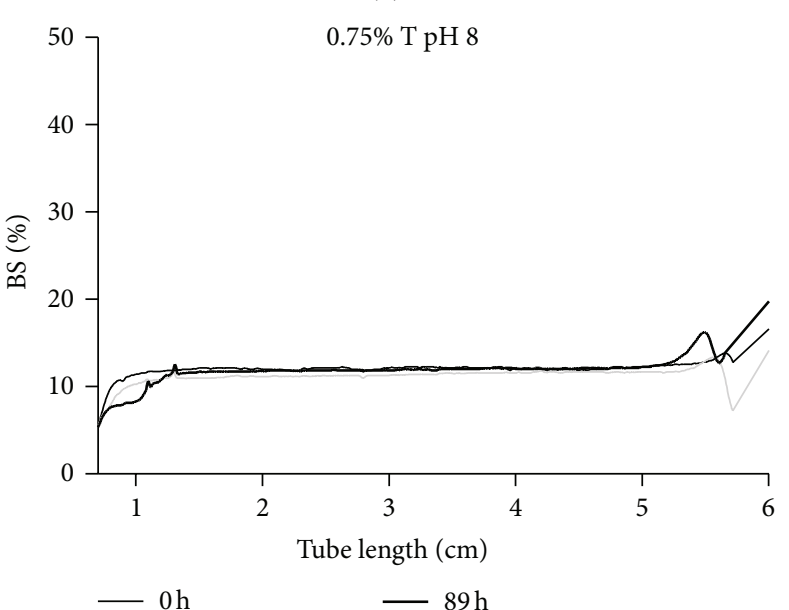

(d)

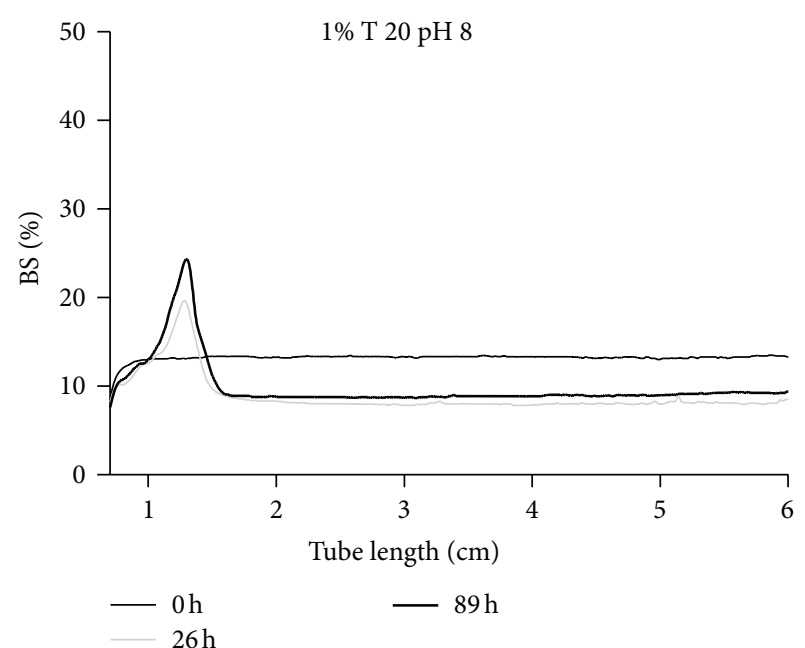

(f)

FIGURE 1: Stability of the emulsions stored at $40^{\circ} \mathrm{C}$, comparing final $\mathrm{pH}$ of the emulsion and the type-concentration of the encapsulating agents. $0.25 \%$ T: $0.25 \% \mathrm{w} / \mathrm{w}$ trehalose; $0.75 \% \mathrm{~T}: 0.75 \% \mathrm{w} / \mathrm{w}$ trehalose; T 20: $1 \% \mathrm{w} / \mathrm{w}$ Tween 20. 


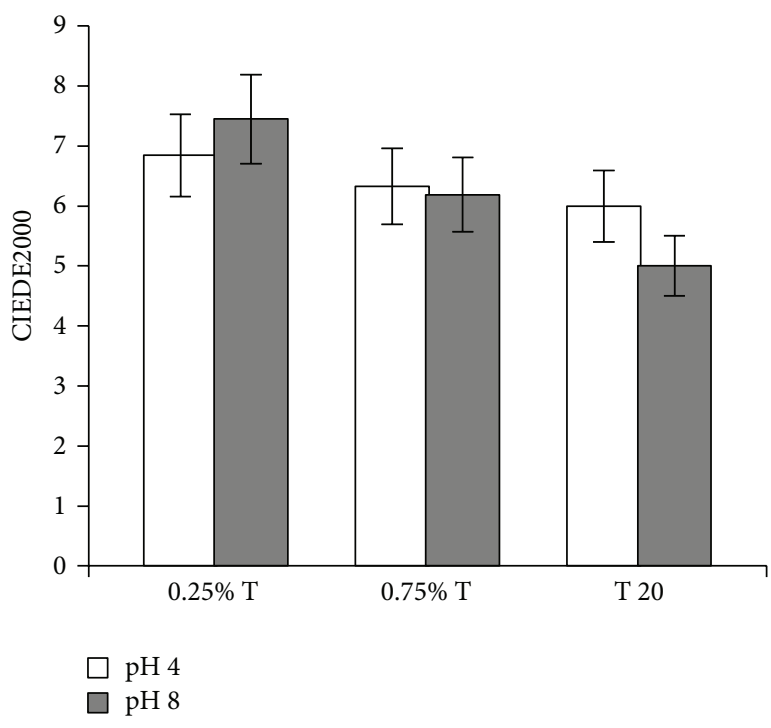

(a)

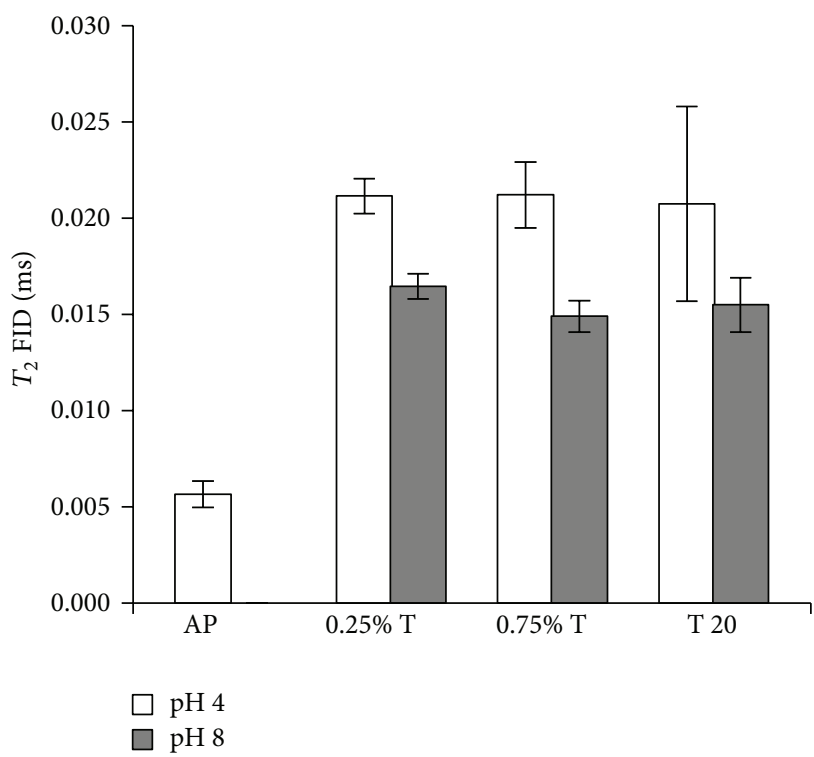

(c)

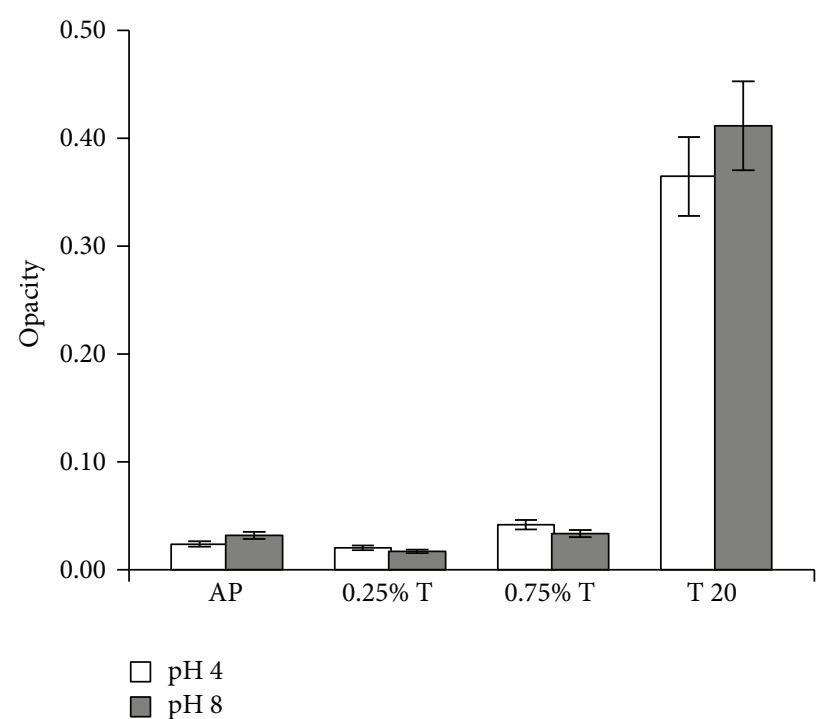

(b)

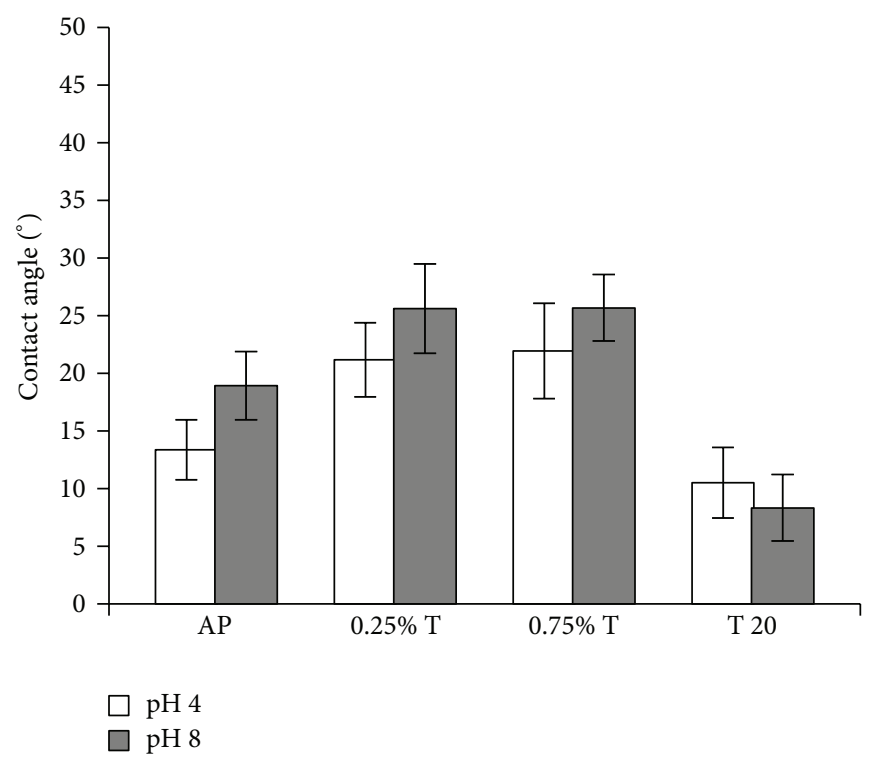

(d)

FIgURE 2: Characterization of each film at initial time at different pH: (a) variation of color (CIEDE2000), (b) opacity, (c) molecular mobility by $\mathrm{T}_{2}$ FID, and (d) contact angle. Bars correspond to standard deviation of mean value. $0.25 \% \mathrm{~T}: 0.25 \% \mathrm{w} / \mathrm{w}$ trehalose; $0.75 \% \mathrm{~T}: 0.75 \% \mathrm{w} / \mathrm{w}$ trehalose; T 20: 1\% w/w Tween 20.

of films were compared with control film (without antimicrobial and encapsulating agents) [42, 43]. Figure 2(a) shows significant differences $(P<0.05)$ between types of encapsulating agent, but not by $\mathrm{pH}$ of films. All studied films showed color variations higher than 5 , indicating perceptible changes on color comparing to control [54].

Opacity, calculated using (2), was also affected by type of encapsulating agent and not by $\mathrm{pH}$ of films (Figure 2(b)). Films containing Tween 20 presented higher opacity (value of $0.35-0.45$ ) than the other agents (lower than 0.05), which are considered transparent [55]. This result was attributed to sedimentation in emulsions as observed in Figures 1(e) and $1(f)$, which subsequently affected formation of the film, principally in opacity. In other way, molecular mobility of the films was affected principally by $\mathrm{pH}(P<0.05)$, showing lower mobility at $\mathrm{pH} 8$ than $\mathrm{pH} 4$ (Figure 2(c)), where no significant differences $(P<0.05)$ were observed by type or concentration of encapsulating agent. Hydrophobicity of the films, measured by contact angle, was affected significantly $(P<0.05)$ by type of encapsulating agent but was not affected by $\mathrm{pH}$ of films (Figure 2(d)). Films containing Tween 20 showed the highest hydrophobicity, due to the nonpolar nature of Tween 20. On the other side, as expected from the hydrophilic nature of trehalose, their addition to films diminished hydrophobicity comparing to alginate films. 


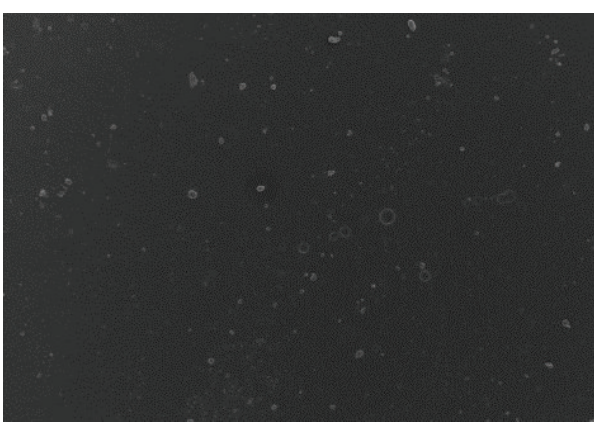

(a)

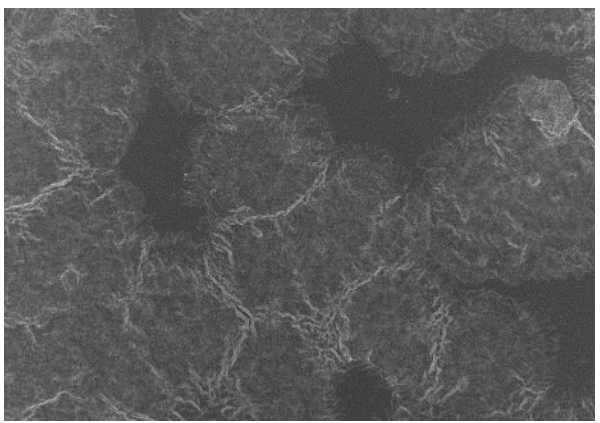

(c)

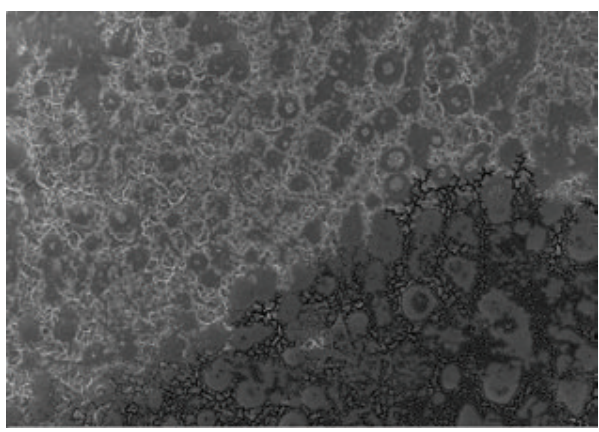

(e)

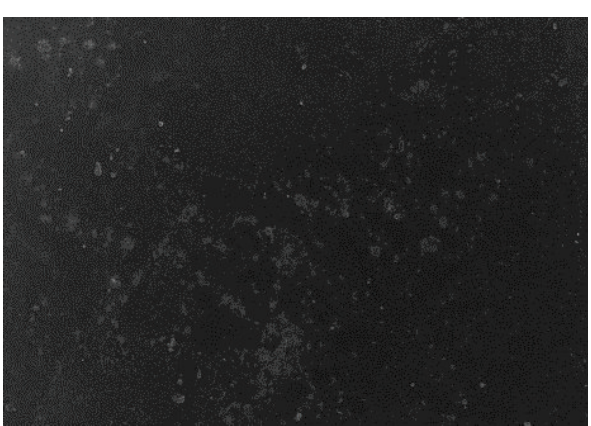

(b)

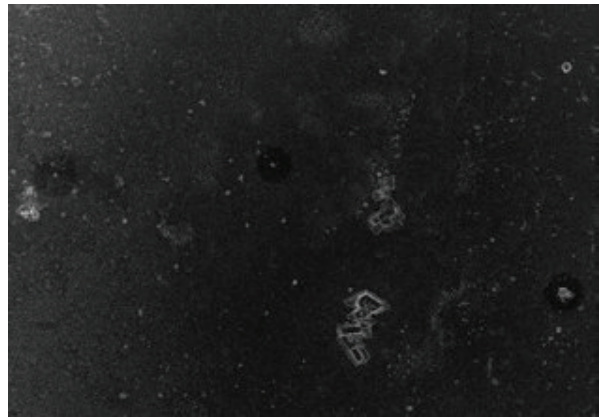

(d)

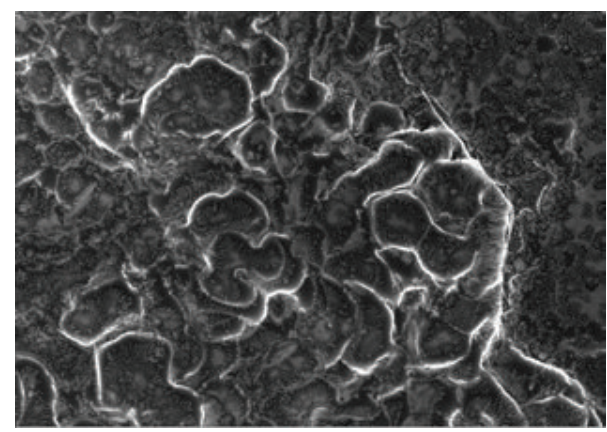

(f)

Figure 3: Scanning electron microscopy of the films at $1000 \mathrm{x}$. (a) $0.25 \% \mathrm{w} / \mathrm{w}$ trehalose $\mathrm{pH} 4$, (b) $0.25 \% \mathrm{w} / \mathrm{w}$ trehalose $\mathrm{pH} 8$, (c) $0.75 \% \mathrm{w} / \mathrm{w}$ trehalose $\mathrm{pH} 4$, (d) $0.75 \% \mathrm{w} / \mathrm{w}$ trehalose $\mathrm{pH} 8$, (e) $1 \% \mathrm{w} / \mathrm{w}$ Tween $20 \mathrm{pH}$ 4, and (f) $1 \% \mathrm{w} / \mathrm{w}$ Tween $20 \mathrm{pH} 8$.

Figure 3 shows the influence of type and concentration of encapsulating agents together with $\mathrm{pH}$ on the surface morphology of films. García et al. [56] reported that films containing lipids showed SEM images with smooth surface and compact structure, indicating an homogenous dispersion (without phase separation) of lipids in the matrix. Films containing trehalose showed a homogenous and soft structure, comparing with Tween 20, which presented a wrinkled structure. However, presence of crystals (Figure 3(d)) was observed at concentration of $0.75 \%$ of trehalose, which was associated with trehalose crystallization. Elizalde et al. [57] observed similar results during encapsulation of carotenoids by freeze-drying in a trehalose/gelatin matrix. Authors explained that sugar crystallization was influenced by water content, which promoted the release of encapsulated lipids.

The efficiency of encapsulation was measured through the $\%$ of release of carvacrol, by (3), where higher release of carvacrol indicates lower efficiency of encapsulation. The results obtained show significant differences $(P<0.05)$ between type and concentration of the encapsulating agents but not by $\mathrm{pH}$. The efficiency of encapsulation was higher at $0.75 \%$ of trehalose, showing a value of $14 \%$ of carvacrol release comparing to $57 \%$ for $0.25 \%$ trehalose and $39 \%$ for Tween 20. This result is indicative that carvacrol was less released at higher concentrations of trehalose, being more encapsulated, and, therefore, it could be expected that it was released in a prolonged way during storage time.

Microbial growth such as E. coli on the surface of a food is a major cause of food spoilage and food-borne illness. Therefore, the use of edible active coating is interesting to inhibit spoilage and pathogenic microorganisms. Figure 4 shows that all parameters evaluated (type and concentration of encapsulating agents and $\mathrm{pH}$ ) showed significant differences $(P<0.05)$ in the inhibition halo except for $\mathrm{pH}$ 


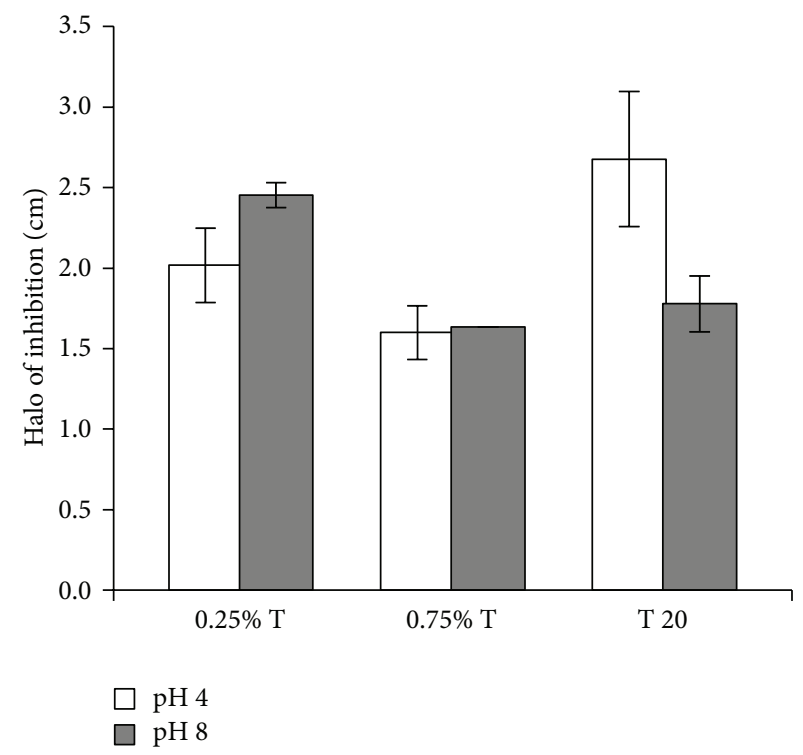

(a)
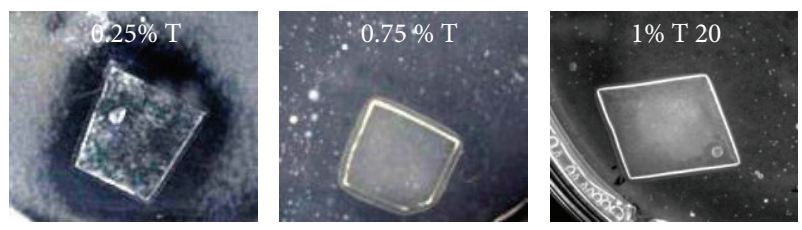

(b)

Figure 4: Halo of inhibition of the films against Escherichia coli by agar diffusion method. (a) Measurements. Bars correspond to standard deviation of mean value of triplicates. $0.25 \% \mathrm{~T}: 0.25 \% \mathrm{w} / \mathrm{w}$ trehalose; $0.75 \%$ T: $0.75 \% \mathrm{w} / \mathrm{w}$ trehalose; T $20: 1 \%$ w/w Tween 20 . (b) Images of halo of inhibition as example.

in samples using $0.75 \%$ of trehalose. The high diffusion of antimicrobial agent and, therefore, higher inhibition were observed for $0.25 \%$ trehalose, followed by Tween 20 and then by $0.75 \%$ trehalose (Figure 4 ). Alginate films containing Tween 20 showed more interactions (measured as numbers of new peaks by FTIR) in comparison with those films containing trehalose [58]. Therefore, these differences in inhibition halo between encapsulating agents may be due to possible interactions between the hydroxyl groups of trehalose or Tween 20 and alginate polymeric chains, affecting therefore the antimicrobial agent release.

\subsection{Characterization of Physical and Antimicrobial Properties} of Films during Storage. Optical properties could change by humidity and temperature during storage conditions. Therefore, opacity and variation of color (CIEDE2000) for each time were evaluated during storage of 14 days comparing with the control film at initial time. Analysis was performed using the experimental design previously described, evaluating $\mathrm{pH}$ of film together with temperature and relative humidity as storage conditions.

Taking into account the results of CDDR experimental design (Table 1) and Pareto diagram for each parameter, it may be concluded that relative humidity is the principal factor that affects significantly $(P<0.05)$ the opacity and variation of color of all evaluated films. In addition, inhibition halo was affected significantly $(P<0.05)$ by humidity and temperature, the antimicrobial activity diminishing as humidity increases, and temperature decreases (data not shown).

The desirability function method helps determine the combination of experimental factors which simultaneously optimizes multiple answers. Therefore, the optima conditions
TABLE 2: Optimal conditions for the function of desirability and optimal responses for the 14 days of storage.

\begin{tabular}{|c|c|c|c|}
\hline Factors & $\begin{array}{l}0.25 \% \\
\text { trehalose }\end{array}$ & $\begin{array}{c}0.75 \% \\
\text { trehalose }\end{array}$ & $1 \%$ Tween 20 \\
\hline \multicolumn{4}{|c|}{ Optimal conditions } \\
\hline $\mathrm{pH}$ & 7 & 8 & 6 \\
\hline Temperature $\left({ }^{\circ} \mathrm{C}\right)$ & 30 & 11 & 26 \\
\hline Relative humidity (\%) & 78 & 75 & 78 \\
\hline \multicolumn{4}{|c|}{ Responses } \\
\hline Variation of color & 1.4 & 3.2 & 2.7 \\
\hline Opacity & 5.5 & 5.3 & 21.6 \\
\hline Halo of inhibition $(\mathrm{cm})$ & 3 & 2.7 & 3 \\
\hline
\end{tabular}

to obtain edible films with antimicrobial activity after 14 days of storage were chosen with the aim of minimizing each property (variation of color and opacity) and of maximizing inhibition of bacteria growth (maxima halo of inhibition). The desirability maxima reached and their responses are observed in Table 2. The responses at each optimal condition showed high inhibition of $E$. coli since inhibition halo was similar to the one observed at initial time (Figure 4). The optimal conditions were similar for relative humidity but varying for $\mathrm{pH}$ and temperature for the three evaluated films. The results showed that these films can be used at "room" storage condition with a 75\% RH. However, other conditions may affect the fresh foods where these films are intended to be applied.

Model verification was performed with an additional three sets of independent trials using the mentioned optimized conditions for each studied films. They were compared 
to the predicted value from the CCRD model. All trials were not significantly $(P>0.05)$ different between them. The coefficient variation $(\mathrm{CV})$ was lower than $10 \%$ and the coefficient of determination $\left(R^{2}\right)$ between experimental values of each evaluated factor and the predicted value suggested by the desirability function was higher than 0.95 . Therefore, the experimental results gave close values to the theoretical prediction, which meant that the results of validation parameters were satisfactory.

The high value of opacity as response of $1 \%$ of Tween 20 (Table 2) indicates that these films have no possibility of industrial applications. On the other hand, taking into account the low values of response corresponding to optical properties and the prolonged antimicrobial activity together with the optimal conditions for these values, it can be assumed that alginate films containing trehalose (at both concentrations) as encapsulating agent of carvacrol can be used as coating in fresh fruits. Taking into account these results, films containing trehalose were evaluated as antifungal films against Botrytis cinerea at the conditions found to be optimal. Films were stored at a relative humidity of $75 \%$ and a room temperature of $20^{\circ} \mathrm{C}$, a mean of optima temperature obtained. The antifungal activity using the vapor phase methodology was evaluated at each storage time. Figure 5 showed the results obtained for inhibition of growth in edible films at both concentrations of trehalose and at different $\mathrm{pH}$ (4 and 8). Significant differences $(P<0.05)$ were obtained with $\mathrm{pH}$ but not with concentration of trehalose $(P>0.05)$, with the best antifungal film being the one prepared at $\mathrm{pH}$ 4. Although the antifungal activity diminished during storage time for films containing trehalose at $\mathrm{pH} 4$, it is important to note that the diminution of fungal growth is higher than $50 \%$, affirming that these films could be used by coating and/or without contact.

\section{Conclusions}

Results showed that the incorporation of trehalose improves the stability of film forming emulsion comparing to Tween 20 , which presents sedimentation as instability mechanism. However, $\mathrm{pH}$ of emulsion was an important factor for its stability, being more stable at $\mathrm{pH} 4$ than $\mathrm{pH}$ 8. Meanwhile, films containing trehalose were transparent comparing to opaque films with Tween 20 and differences on surface microstructure were observed between them.

During storage time, the different studied films presented different optima values of $\mathrm{pH}$, relative humidity, and temperature to minimize responses as opacity and color variation and to maximize inhibition growth of bacteria. However, taking into account the multiple responses, the value of $\mathrm{RH}$ selected was $75 \%$, but $\mathrm{pH}$ value and temperature was depending on the composition of each film. The responses observed of films stored at these optima conditions for 14 days showed that films containing trehalose (at both concentrations) are the most suitable to use in fresh foods stored at temperatures between 22 and $30^{\circ} \mathrm{C}$ and relative humidity of $75 \%$. However, antifungal effect was depending on $\mathrm{pH}$ more than concentration of trehalose and was observed during 30 days of storage, where the inhibition of $B$. cinerea was higher

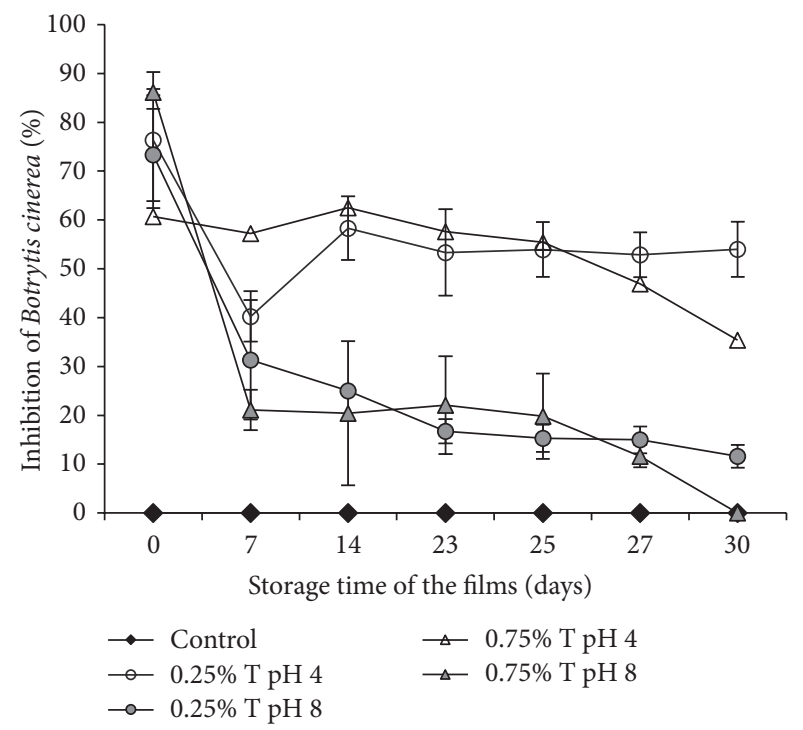

FIGURE 5: Inhibition percentage of growth of Botrytis cinerea using vapour phase methodology during storage time of the films. Bars indicate standard deviation of mean value of triplicates. $0.25 \% \mathrm{~T}$ : $0.25 \% \mathrm{w} / \mathrm{w}$ trehalose; $0.75 \%$ T: $0.75 \% \mathrm{w} / \mathrm{w}$ trehalose.

than $50 \%$ at $\mathrm{pH}$ 4. Taking into account the microscopy of surface where crystals were observed at high concentration of trehalose, the best edible film was the sample with $0.25 \%$ trehalose at $\mathrm{pH}$ 4. Therefore, an antibacterial and antifungal alginate/trehalose edible film incorporated with carvacrol is a promising packaging material with good potential in many food applications.

\section{Conflict of Interests}

The authors declare that there is no conflict of interests regarding the publication of this paper.

\section{Acknowledgments}

The authors acknowledge financial support from FONDECYT Project no. 1131017, DICYT Project from VRIDEI of University of Santiago of Chile; Programa Escala Docente AUGM, Universidad de Buenos Aires-Universidad de Santiago de Chile, UBACYT Project no. 20020130100136BA.

\section{References}

[1] A. Ali, M. Maqbool, S. Ramachandran, and P. G. Alderson, "Gum arabic as a novel edible coating for enhancing shelflife and improving postharvest quality of tomato (Solanum lycopersicum L.) fruit," Postharvest Biology and Technology, vol. 58, no. 1, pp. 42-47, 2010.

[2] C. A. Campos, L. N. Gerschenson, and S. K. Flores, "Development of edible films and coatings with antimicrobial activity," Food and Bioprocess Technology, vol. 4, no. 6, pp. 849-875, 2011.

[3] A. M. Durango, N. F. F. Soares, and N. J. Andrade, "Microbiological evaluation of an edible antimicrobial coating on minimally processed carrots," Food Control, vol. 17, no. 5, pp. 336-341, 2006. 
[4] G. Oms-Oliu, M. A. Rojas-Graü, L. A. González et al., "Recent approaches using chemical treatments to preserve quality of fresh-cut fruit: a review," Postharvest Biology and Technology, vol. 57, no. 3, pp. 139-148, 2010.

[5] M. A. Rojas-Graü, R. Soliva-Fortuny, and O. Martín-Belloso, "Edible coatings to incorporate active ingredients to fresh-cut fruits: a review," Trends in Food Science and Technology, vol. 20, no. 10, pp. 438-447, 2009.

[6] K. G. Zinoviadou, K. P. Koutsoumanis, and C. G. Biliaderis, "Physico-chemical properties of whey protein isolate films containing oregano oil and their antimicrobial action against spoilage flora of fresh beef," Meat Science, vol. 82, no. 3, pp. 338345, 2009.

[7] M. A. Rojas-Graü, R. J. Avena-Bustillos, M. Friedman, P. R. Henika, O. Martín-Belloso, and T. H. Mchugh, "Mechanical, barrier, and antimicrobial properties of apple puree edible films containing plant essential oils," Journal of Agricultural and Food Chemistry, vol. 54, no. 24, pp. 9262-9267, 2006.

[8] M. A. Rojas-Graü, R. J. Avena-Bustillos, C. Olsen et al., "Effects of plant essential oils and oil compounds on mechanical, barrier and antimicrobial properties of alginate-apple puree edible films," Journal of Food Engineering, vol. 81, no. 3, pp. 634-641, 2007.

[9] W.-X. Du, C. W. Olsen, R. J. Avena-Bustillos, T. H. McHugh, C. E. Levin, and M. Friedman, "Storage stability and antibacterial activity against Escherichia coli O157:H7 of carvacrol in edible apple films made by two different casting methods," Journal of Agricultural and Food Chemistry, vol. 56, no. 9, pp. 3082-3088, 2008.

[10] W.-X. Du, C. W. Olsen, R. J. Avena-Bustillos, T. H. McHugh, C. E. Levin, and M. Friedman, "Antibacterial activity against E. coli $\mathrm{O} 157: \mathrm{H} 7$, physical properties, and storage stability of novel carvacrol-containing edible tomato films," Journal of Food Science, vol. 73, no. 7, pp. M378-M383, 2008.

[11] L. Hernández-Ochoa, C. A. MacÍas-Castanãeda, G. V. NevárezMoorillón, E. Salas-Munãoz, and F. Sandoval-Salas, "Antimicrobial activity of chitosan-based films including spices essential oils and functional extracts," CyTA-Journal of Food, vol. 10, no. 2, pp. 85-91, 2012.

[12] J. Gómez-Estaca, L. Bravo, M. C. Gómez-Guillén, A. Alemán, and P. Montero, "Antioxidant properties of tuna-skin and bovine-hide gelatin films induced by the addition of oregano and rosemary extracts," Food Chemistry, vol. 112, no. 1, pp. 1825, 2009.

[13] A. A. M. de Melo, M. G. Robson, M. F. Araujo Silveira et al., "Microbiological quality and other characteristics of refrigerated chicken meat in contact with cellulose acetatebased film incorporated with rosemary essential oil," Brazilian Journal of Microbiology, vol. 43, no. 4, pp. 1419-1427, 2012.

[14] I. Fernández-Pan, X. Carrión-Granda, and J. I. Maté, "Antimicrobial efficiency of edible coatings on the preservation of chicken breast fillets," Food Control, vol. 36, no. 1, pp. 69-75, 2014.

[15] D. López, N. Acevedo, and S. Matiacevich, "Characterization of edible active coating based on alginate-thyme oil-propionic acid for the preservation of fresh chicken breast fillets," Journal of Food Processing and Preservation, 2015.

[16] R. M. Raybaudi-Massilia, J. Mosqueda-Melgar, and O. MartínBelloso, "Edible alginate-based coating as carrier of antimicrobials to improve shelf-life and safety of fresh-cut melon," International Journal of Food Microbiology, vol. 121, no. 3, pp. 313-327, 2008.
[17] A. C. Guerreiro, C. M. L. Gago, M. L. Faleiro, M. G. C. Miguel, and M. D. C. Antunes, "The effect of alginate-based edible coatings enriched with essential oils constituents on Arbutus unedo L. fresh fruit storage," Postharvest Biology and Technology, vol. 100, pp. 226-233, 2015.

[18] M. A. Rojas-Graü, R. M. Raybaudi-Massilia, R. C. SolivaFortuny, R. J. Avena-Bustillos, T. H. McHugh, and O. MartínBelloso, "Apple puree-alginate edible coating as carrier of antimicrobial agents to prolong shelf-life of fresh-cut apples," Postharvest Biology and Technology, vol. 45, no. 2, pp. 254-264, 2007.

[19] L. Keawchaoon and R. Yoksan, "Preparation, characterization and in vitro release study of carvacrol-loaded chitosan nanoparticles," Colloids and Surfaces B: Biointerfaces, vol. 84, no. 1, pp. 163-171, 2011.

[20] T. Kulisic, A. Radonic, V. Katalinic, and M. Milos, "Use of different methods for testing antioxidative activity of oregano essential oil," Food Chemistry, vol. 85, no. 4, pp. 633-640, 2004.

[21] S. Burt, "Essential oils: their antibacterial properties and potential applications in foods-a review," International Journal of Food Microbiology, vol. 94, no. 3, pp. 223-253, 2004.

[22] S. Benavides, R. Villalobos-Carvajal, and J. E. Reyes, "Physical, mechanical and antibacterial properties of alginate film: effect of the crosslinking degree and oregano essential oil concentration," Journal of Food Engineering, vol. 110, no. 2, pp. 232-239, 2012.

[23] A. Guarda, J. F. Rubilar, J. Miltz, and M. J. Galotto, "The antimicrobial activity of microencapsulated thymol and carvacrol," International Journal of Food Microbiology, vol. 146, no. 2, pp. 144-150, 2011.

[24] P. M. Periago, B. Delgado, P. S. Fernández, and A. Palop, "Use of carvacrol and cymene to control growth and viability of Listeria monocytogenes cells and predictions of survivors using frequency distribution functions," Journal of Food Protection, vol. 67, no. 7, pp. 1408-1416, 2004.

[25] M. M. Tajkarimi, S. A. Ibrahim, and D. O. Cliver, "Antimicrobial herb and spice compounds in food," Food Control, vol. 21, no. 9, pp. 1199-1218, 2010.

[26] D. J. Daferera, B. N. Ziogas, and M. G. Polissiou, "The effectiveness of plant essential oils on the growth of Botrytis cinerea, Fusarium sp. and Clavibacter michiganensis subsp. michiganensis," Crop Protection, vol. 22, no. 1, pp. 39-44, 2003.

[27] D. S. Arora and J. Kaur, "Antimicrobial activity of spices," International Journal of Antimicrobial Agents, vol. 12, no. 3, pp. 257-262, 1999.

[28] J. Kester and O. Fennema, "Edible films and coatings: a review," Food Technology, vol. 40, pp. 47-59, 1986.

[29] A. Acevedo-Fani, L. Salvia-Trujillo, M. A. Rojas-Graü, and O. Martín-Belloso, "Edible films from essential-oil-loaded nanoemulsions: physicochemical characterization and antimicrobial properties," Food Hydrocolloids, vol. 47, pp. 168-177, 2015.

[30] K. C. Aguilar, F. Tello, A. C. K. Bierhalz, M. G. Garnica Romo, H. E. Martínez Flores, and C. R. F. Grosso, "Protein adsorption onto alginate-pectin microparticles and films produced by ionic gelation," Journal of Food Engineering, vol. 154, pp. 17-24, 2015.

[31] J. W. Rhim, J. H. Kim, and D. H. Kim, "Modification of Naalginate films by $\mathrm{CaCl} 2$ treatment," Korean Journal of Food Science and Technology, vol. 37, pp. 217-221, 2003.

[32] J.-W. Rhim, "Physical and mechanical properties of water resistant sodium alginate films," LWT-Food Science and Technology, vol. 37, no. 3, pp. 323-330, 2004. 
[33] M. S. Álvarez-Cerimedo, M. Cerdeira, R. J. Candal, and M. L. Herrera, "Microencapsulation of a low-trans fat in trehalose as affected by emulsifier type," Journal of the American Oil Chemists' Society, vol. 85, no. 9, pp. 797-807, 2008.

[34] D. Celis, M. I. Azócar, J. Enrione, M. Páez, and S. Matiacevich, "Influence of glassy or rubbery state on antimicrobial properties of chitosan-gelatin films," Journal of Food Research, vol. 1, pp. 184-193, 2012.

[35] S. Matiacevich, D. C. Cofré, C. Schebor, and J. Enrione, "Physicochemical and antimicrobial properties of bovine and salmon gelatin-chitosan films," CyTA-Journal of Food, vol. 11, no. 4, pp. 366-378, 2013.

[36] Y. Elad, B. Williamson, P. Tudzinsky, and N. Delen, Botrytis: Biology, Phatology and Control, Springer, Dordrecht, The Netherlands, 2007.

[37] K. Di Scipio, Y. Escalona, K. Quijada, and F. Millán, “Estudio del mezclado de emulsiones aplicando la metodología de superficie respuesta," Revista de la Facultad de Ingeniería UCV, vol. 23, pp. 3-7, 2008.

[38] M. Torab-Mostaedi, J. Safdari, and A. Ghaemi, "Mass transfer coefficients in pulsed perforated-plate extraction columns," Brazilian Journal of Chemical Engineering, vol. 27, no. 2, pp. 243251, 2010.

[39] M. Cerdeira, G. G. Palazolo, R. J. Candal, and M. L. Herrera, "Factors affecting initial retention of a microencapsulated sunflower seed oil/milk fat fraction blend," Journal of the American Oil Chemists' Society, vol. 84, no. 6, pp. 523-531, 2007.

[40] F. Pedreschi, J. León, D. Mery, and P. Moyano, "Development of a computer vision system to measure the color of potato chips," Food Research International, vol. 39, no. 10, pp. 1092-1098, 2006.

[41] S. Matiacevich, P. Silva, F. Osorio, and J. Enrione, "Evaluation of blueberry colour during storage using image analysis," in Colour in Food: Technological and Psychophysical Aspects, J. L. Caivano and M. P. Buera, Eds., pp. 211-218, CRC Publisher, Buenos Aires, Argentina, 2012.

[42] M. R. Luo, G. Cui, and B. Rigg, "The development of the CIE 2000 colour-difference formula: CIEDE2000," Color Research \& Application, vol. 26, no. 5, pp. 340-350, 2001.

[43] G. Sharma, W. Wu, and E. N. Dalal, "The CIEDE2000 colordifference formula: implementation notes, supplementary test data, and mathematical observations," Color Research and Application, vol. 30, no. 1, pp. 21-30, 2005.

[44] P. A. Ponce Cevallos, M. P. Buera, and B. E. Elizalde, "Encapsulation of cinnamon and thyme essential oils components (cinnamaldehyde and thymol) in $\beta$-cyclodextrin: effect of interactions with water on complex stability," Journal of Food Engineering, vol. 99, no. 1, pp. 70-75, 2010.

[45] E. W. Hansen, P. E. Kristiansen, and B. Pedersen, "Crystallinity of polyethylene derived from solid-state proton NMR free induction decay," The Journal of Physical Chemistry B, vol. 102, no. 28, pp. 5444-5450, 1998.

[46] Centers for Disease Control and Prevention (CDC) and World Health Organization (WHO), Manual for the Laboratory Identification and Antimicrobial Susceptibility Testing of Bacterial Pathogens of Public Health Importance in the Developing World, Centers for Disease Control and Prevention (CDC), World Health Organization (WHO), 2003.

[47] S. Inouye, M. Watanabe, Y. Nishiyama, K. Takco, M. Akao, and H. Yamaguchi, "Antisporulating and respiration-inhibitory effects of essential oils on filamentous fungi," Mycoses, vol. 41, no. 9-10, pp. 403-410, 1998.
[48] V. Tullio, A. Nostro, N. Mandras et al., "Antifungal activity of essential oils against filamentous fungi determined by broth microdilution and vapour contact methods," Journal of Applied Microbiology, vol. 102, no. 6, pp. 1544-1550, 2007.

[49] K. Laird and C. Phillips, "Vapour phase: a potential future use for essential oils as antimicrobials?" Letters in Applied Microbiology, vol. 54, no. 3, pp. 169-174, 2012.

[50] M. J. Velázquez-Nuñez, R. Avila-Sosa, E. Palou, and A. LópezMalo, "Antifungal activity of orange (Citrus sinensis var. Valencia) peel essential oil applied by direct addition or vapor contact," Food Control, vol. 31, no. 1, pp. 1-4, 2013.

[51] L. Greenspan, "Humidity fixed points of binary saturated aqueous solutions," Journal of Research of the National Bureau of Standards A: Physics and Chemistry, vol. 81, no. 1, 1977.

[52] A. E. Edris and C. F. R. Malone, "Preferential solubilization behaviours and stability of some phenolic-bearing essential oils formulated in different microemulsion systems," International Journal of Cosmetic Science, vol. 34, no. 5, pp. 441-450, 2012.

[53] K. Ziani, Y. Fang, and D. J. McClements, "Fabrication and stability of colloidal delivery systems for flavor oils: effect of composition and storage conditions," Food Research International, vol. 46, no. 1, pp. 209-216, 2012.

[54] Y. Yang, J. Ming, and N. Yu, "Color image quality assessment based on CIEDE2000," Advances in Multimedia, vol. 2012, Article ID 273723, 6 pages, 2012.

[55] S. Banerjee and S. Bhattacharya, "Compressive textural attributes, opacity and syneresis of gels prepared from gellan, agar and their mixtures," Journal of Food Engineering, vol. 102, no. 3, pp. 287-292, 2011.

[56] M. A. García, A. Pinotti, M. N. Martino, and N. E. Zaritzky, "Characterization of starch and composite edible films and coatings," in Edible Films and Coatings for Food Applications, M. E. Embuscado and K. C. Huber, Eds., pp. 169-210, Springer, New York, NY, USA, 2009.

[57] B. E. Elizalde, M. L. Herrera, and M. P. Buera, "Retention of $\beta$ carotene encapsulated in a trehalose-based matrix as affected by water content and sugar crystallization," Journal of Food Science, vol. 67, no. 8, pp. 3039-3045, 2002.

[58] R. Navarro, C. Arancibia, M. L. Herrera, and S. Matiacevich, "Effect of type of encapsulating agent on physical properties of edible films based on alginate and thyme oil," Food and Bioproducts Processing, In press. 

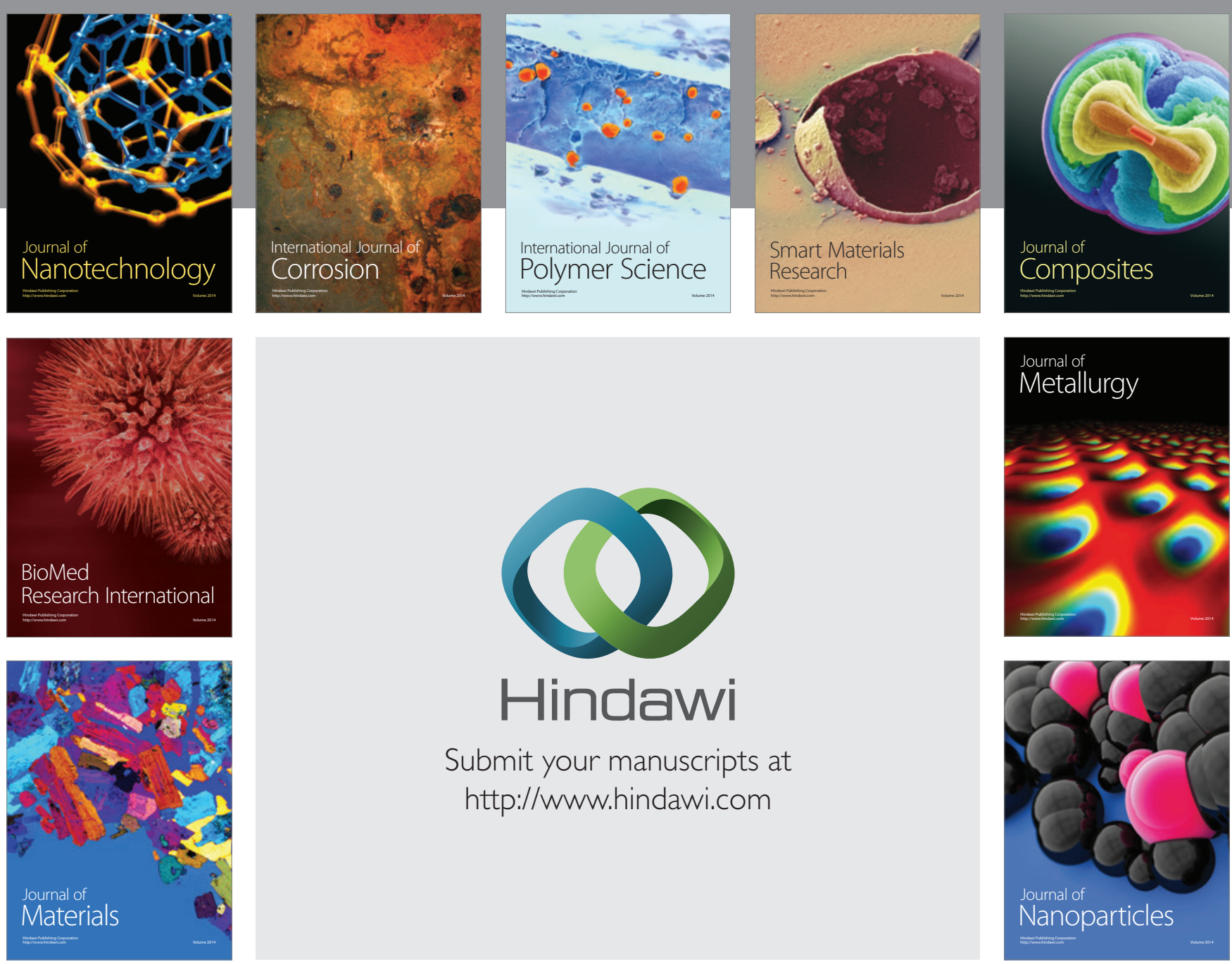

Submit your manuscripts at http://www.hindawi.com
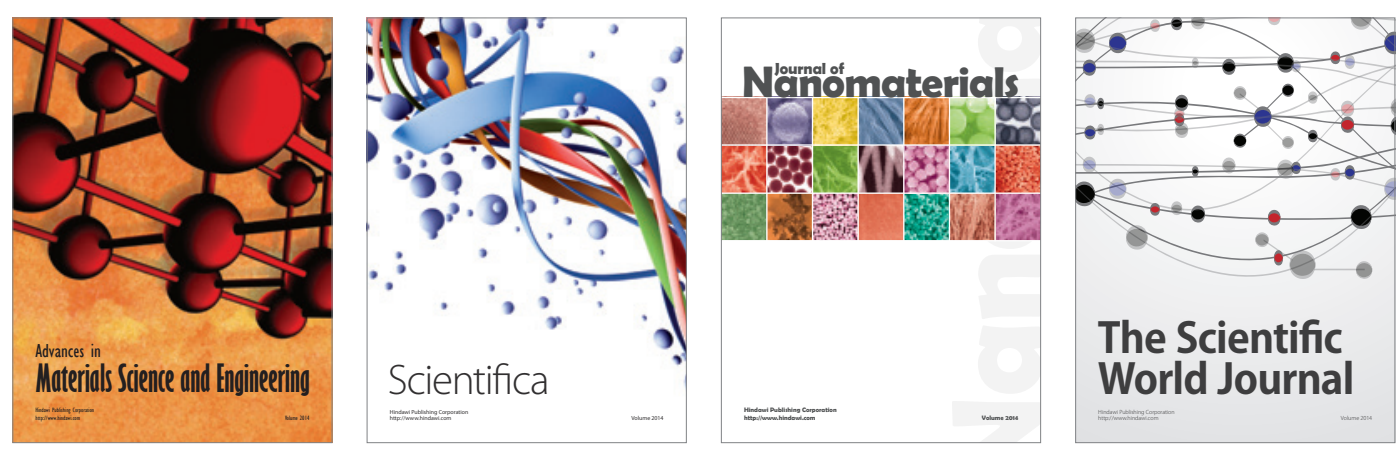

\section{The Scientific World Journal}
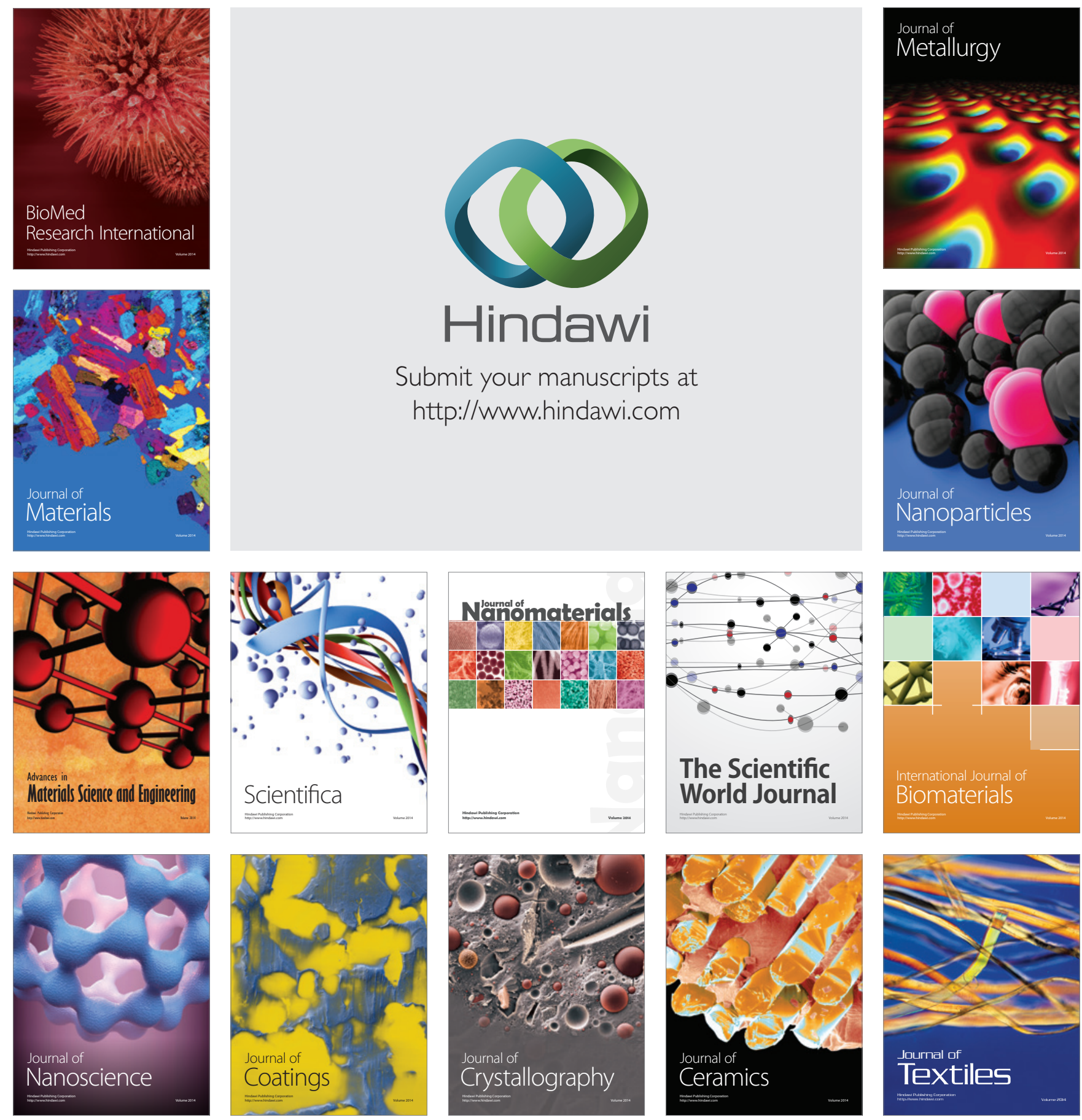